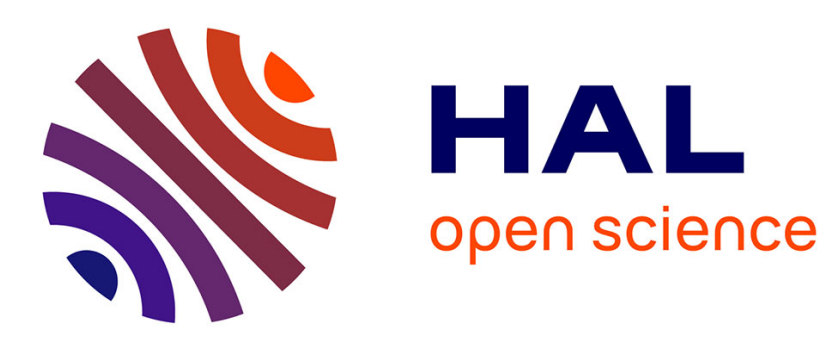

\title{
The behaviour of the normal fluctuation terms in the case of attached and detached turbulent boundary-layers
}

\author{
G.A. Gerolymos, Y.N. Kallas, K.D. Papailiou
}

\section{To cite this version:}

G.A. Gerolymos, Y.N. Kallas, K.D. Papailiou. The behaviour of the normal fluctuation terms in the case of attached and detached turbulent boundary-layers. Revue de Physique Appliquée, 1989, 24 (3), pp.375-387. 10.1051/rphysap:01989002403037500 . jpa-00246060

\section{HAL Id: jpa-00246060 https://hal.science/jpa-00246060}

Submitted on 1 Jan 1989

HAL is a multi-disciplinary open access archive for the deposit and dissemination of scientific research documents, whether they are published or not. The documents may come from teaching and research institutions in France or abroad, or from public or private research centers.
L'archive ouverte pluridisciplinaire HAL, est destinée au dépôt et à la diffusion de documents scientifiques de niveau recherche, publiés ou non, émanant des établissements d'enseignement et de recherche français ou étrangers, des laboratoires publics ou privés. 


\title{
The behaviour of the normal fluctuation terms in the case of attached and detached turbulent boundary-layers
}

\author{
G. A. Gerolymos, Y. N. Kallas and K. D. Papailiou \\ National Technical University, Athens, Greece
}

(Reçu le 2 mai 1988, révisé le 30 août 1988, accepté le 27 septembre 1988)

\begin{abstract}
Résumé. - Il a été établi par des mesures expérimentales que quand une couche limite turbulente s'approche du décollement, décolle ou interagit avec une onde de choc, les termes de fluctuation turbulente augmentent en valeur et exercent une influence importante sur le bilan de quantité de mouvement du fluide. En conséquence les intégrales des termes normaux de fluctuation devraient être prises en compte dans des formulations intégrales pour le calcul des couches limites turbulentes. Dans le présent travail des données expérimentales sont examinées, dans le but de déterminer des corrélations entre ces intégrales et des quantités de l'écoulement moyen. Les corrélations qui sont élaborées sont valables pour des couches limites attachées et décollées, compressibles et incompressibles. Elles sont aussi valables pour des écoulements d'interaction onde de choc/couche limite turbulente. En plus, des corrélations sont élaborées pour les maxima des fluctuations normales. Finalement, la structure de la turbulence dans des couches limites décollées est discutée.
\end{abstract}

\begin{abstract}
Experimental measurements have established that when a turbulent boundary-layer approaches separation, separates or interacts with a shock-wave, the turbulence normal fluctuation terms increase in magnitude and exert an appreciable influence upon fluid-momentum balance. Consequently, the integrals of the normal fluctuation terms should be included in integral formulations for the calculation of turbulent boundary-layers. In the present work, available experimental data are examined in view of establishing correlations between these integrals and mean-flow quantities. The correlations that are elaborated are valid both for attached and detached, incompressible and compressible turbulent boundary-layers. They are also valid for shock-wave/turbulent boundary-layer interaction flows. Furthermore correlations for the maxima of the normal fluctuation terms are presented. Finally the turbulence structure in separated boundary-layers is discussed.
\end{abstract}

\section{Nomenclature :}

$\alpha \quad=$ anisotropy (Eq. (13))

$A=$ normal fluctuations integral in the mean momentum equation (Eq. (3))

$B=$ normal fluctuations integral in the mean energy equation (Eq. (4))

$C_{\mathrm{d}}=$ dissipation-factor $\left\{\int_{0}^{\delta}\left(\bar{\phi} / \rho_{\mathrm{e}} u_{\mathrm{e}}^{3}\right) \mathrm{d} y\right\}$

$C_{\mathrm{f}}=$ skin-friction coefficient $\left\{2 \tau_{\mathrm{w}} / \rho_{\mathrm{e}} u_{\mathrm{e}}^{2}\right\}$

$H_{12}=$ boundary-layer shape-factor $\left\{\delta_{1} / \delta_{2}\right\}$

$H_{13}=$ boundary-layer shape-factor $\left\{\delta_{1} / \delta_{3}\right\}$

$J_{12}=$ boundary-layer shape-parameter

$$
\left\{1-1 / H_{12}\right\}
$$

$\ell_{\mathrm{k}} \quad=$ boundary-layer length-scale (Eq. (7))

$M=$ Mach-number

$p \quad=$ static pressure

$r \quad=$ wall-temperature recovery-factor

$u=$ velocity-component parallel to the wall $u_{\tau}=$ friction-velocity $\left\{\operatorname{sign}\left(\tau_{\mathrm{w}}\right) \sqrt{\left|\tau_{\mathrm{w}}\right| / \rho_{\mathrm{w}}}\right\}$

$v \quad=$ velocity-component normal to the wall

$x=$ coordinate parallel to the wall

$y=$ coordinate normal to the wall

$w=$ transverse velocity-component

$\gamma \quad=$ isentropic exponent

$\delta=$ boundary-layer thickness

$\delta_{1}=$ displacement thickness

$$
\left\{\int_{0}^{\delta}\left(1-\bar{\rho} \bar{u} / \rho_{\mathrm{e}} u_{\mathrm{e}}\right) \mathrm{d} y\right\}
$$

$\delta_{2}=$ momentum thickness

$$
\left\{\int_{0}^{\delta}\left[\left(1-\bar{u} / u_{\mathrm{e}}\right) \bar{\rho} \bar{u} / \rho_{\mathrm{e}} u_{\mathrm{e}}\right] \mathrm{d} y\right\}
$$

$\delta_{3}=$ energy thickness

$$
\left\{\int_{0}^{\delta}\left[\left(1-\bar{u}^{2} / u_{\mathrm{e}}^{2}\right) \bar{\rho} \bar{u} / \rho_{\mathrm{e}} u_{\mathrm{e}}\right] \mathrm{d} y\right\}
$$


$\beta=$ equilibrium-parameter (Eq. (11))

$\xi \quad=$ dimensionless length (Eq. (16))

$\rho \quad=$ density

$\tau \quad=$ shear-stress

$\Phi=$ dimensionless velocity (Eq. (15))

$\bar{\phi} \quad=$ turbulent dissipation

$$
\overline{\left\{\frac{1}{2} \mu\left(\frac{\partial u_{i}}{\partial x_{j}}+\frac{\partial u_{j}}{\partial x_{i}}\right)\left(\frac{\partial u_{i}}{\partial x_{j}}+\frac{\partial u_{j}}{\partial x_{i}}\right)\right\}}
$$

Subscripts

$e \quad=$ external flow

$k=$ kinematic value

$w$ = wall-value

$N$ = value at the maximum backflow-velocity location

$\max =$ maximum value in the boundary-layer

Superscripts

$(\bar{\bullet})=$ mean quantity

$(\cdot)^{\prime}=$ fluctuating quantity

\section{Introduction.}

Early measurements in turbulent boundary-layers had established that the turbulence normal fluctuation terms $\overline{u^{\prime 2}}, \overline{v^{\prime 2}}, \overline{w^{\prime 2}}$ which appear in the ensemble-averaged Navier-Stokes equations [1] increase when the boundary-layer approaches separation [2, 3]. Detailed measurements in flows with large separation $[4,5,6]$ confirmed this and showed that the turbulence normal fluctuation terms increase rapidly in the separated flow region, so that their effect on mean fluid momentum balance becomes substantial. The same phenomenon is observed in shock-wave/turbulent boundary-layer interactions both when the boundary-layer separates [7] or not $[8,9]$. Furthermore their value remains important in reattaching turbulent boundary-layers $[10,11]$.

Computer power growth has favorized the development of field methods for viscous flow computations [12, 13]. However, integral methods for boundary-layer calculations are of current use in applications where computing speed is essential, such as aerodynamic design. Most integral boundary-layer computation methods are based on the solution of 2 integral equations for the evolution of the momentum and energy thickness, respectively.

If the normal fluctuation terms are not neglected, the integral mean momentum equation takes the following form [15]

$$
\begin{aligned}
& \mathrm{d} \delta_{2}+\delta_{2}\left(2+H_{12}-\right.\left.M_{\mathrm{e}}^{2}\right) \\
& \frac{\mathrm{d} u_{\mathrm{e}}}{u_{\mathrm{e}}}=C_{\mathrm{f}} \frac{\mathrm{d}_{x}}{2}+ \\
&+\mathrm{d}\left(\int_{0}^{\delta} \bar{\rho} \frac{\overline{u^{\prime 2}}-\overline{v^{\prime 2}}}{\rho_{\mathrm{e}} u_{\mathrm{e}}^{2}} \mathrm{~d} y\right) .
\end{aligned}
$$

By replacing the turbulence production term which appears in the mean kinetic energy equation by the appropriate balance indicated by the turbulence kinetic energy equation, the integral mean kinetic energy equation takes the following form [15]

$$
\begin{aligned}
\mathrm{d} \delta_{3}+ & \delta_{3}\left(3+[r(\gamma-1)-1] M_{\mathrm{e}}^{2}\right) \frac{\mathrm{d} u_{\mathrm{e}}}{u_{\mathrm{e}}}= \\
= & 2 C_{\mathrm{d}} \mathrm{d} x+\mathrm{d}\left(\int_{0}^{\delta} \bar{\rho} \bar{u} \frac{\overline{u^{\prime 2}}+\overline{v^{\prime 2}}+\overline{w^{\prime 2}}}{\rho_{\mathrm{e}} u_{\mathrm{e}}^{3}} \mathrm{~d} y\right)+ \\
& +2 \mathrm{~d}\left(\int_{0}^{\delta} \bar{\rho} \bar{u} \frac{\overline{u^{\prime 2}}-\overline{v^{\prime 2}}}{\rho_{\mathrm{e}} u_{\mathrm{e}}^{3}} \mathrm{~d} y\right)
\end{aligned}
$$

In the following attention will be focused on the terms

$$
A=\int_{0}^{\delta} \frac{\bar{\rho}}{\rho_{\mathrm{e}}} \frac{\overline{u^{\prime 2}}-\overline{v^{\prime 2}}}{u_{\mathrm{e}}^{2}} \mathrm{~d} y
$$

appearing in equation (1) and

$$
B=\int_{0}^{\delta} \frac{\bar{\rho} \bar{u}}{\rho_{\mathrm{e}} u_{\mathrm{e}}} \frac{3 \overline{u^{\prime 2}}-\overline{v^{\prime 2}}+\overline{w^{\prime 2}}}{u_{\mathrm{e}}^{2}} \mathrm{~d} y
$$

appearing in equation (2) (a combination of the 2 nd and 3rd right-hand-side terms).

Most prediction methods neglect the terms $A$ and $B$. Experience with a particular integral method [1618] has indicated that separation could not be well predicted unless these terms were included in the formulation. A first model for these terms [18, 19] which proved to work well for attached boundarylayers was found to be inadequate for separated ones. Furthermore, recent measurements provide the possibility to validate turbulence models in the separated flow region where few reliable and detailed measurements existed in the past.

The purpose of the present work is to analyse available experimental data in order to formulate models for the terms $A$ and $B$, defined in equations (3) and (4) respectively. These models should be applicable both to attached and detached compressible turbulent boundary-layers including the case of shock-wave/turbulent boundary-layer interaction. It will be attempted, as in reference [18], to correlate these terms with mean-flow quantities. In this way, turbulence closure in the mathematical formulation of integral turbulent boundary-layer computation methods may be obtained without solving any additional integral turbulence transport equation. Furthermore, the turbulence structure in nonequilibrium turbulent boundary-layers is investigated, with special emphasis on flows with large separation. It will be shown in the following that it is possible to elaborate correlations for the maximum profile values of the normal fluctuation terms, which are valid in the entire range of boundary-layer flows that were examined. 


\section{Experimental Data.}

The data used in this work are taken from 5 well documented experiments, the main features of which are summarized in table I. They cover a wide range of external-flow Mach-numbers and boundary-layer shape-factors, including 2 cases of transonic shock-wave/turbulent boundary-layer interaction. Accurate and detailed measurements of mean-flow quantities and Reynolds-stresses are available in the references cited in table $I$.

The transverse velocity-fluctuation was not measured in experiments 3 and 4 (Tab. I). Its value is necessary for computing $\mathrm{B}$ (Eq. (4)). It was assumed that $\left(\overline{w^{\prime 2}}=\overline{v^{\prime 2}}\right)$ everywhere $\overline{w^{\prime 2}}$ was not measured. This assumption is based on the data of Simpson, Chew and Shivaprasad in experiment 2, who concluded [6] that $\left(\overline{w^{\prime 2}}=\overline{v^{\prime 2}}\right)$ in the outer $90 \%$ of the layer, both upstream and downstream of separation. It should however be noted that Schubauer and Klebanoff [24] found that $\left(2 \overline{w^{\prime 2}}=\right.$ $\left.\overline{u^{\prime 2}}+\overline{v^{\prime 2}}\right)$ in a zero pressure-gradient turbulent boundary-layer. Furthermore, Acharya [25] studying the effects of compressibility on boundary-layer turbulence found that in the Mach-number range from 0.2 to $0.6, \overline{w^{\prime 2}}$ increases with respect to the value established by Klebanoff as the external-flow Mach-number increases. However, Acharya mentions the presence of secondary-flows in the measuring section which could account for the elevated values of $\overline{w^{\prime 2}}$. No data on flow 2-dimensionality are available for the experiment of Schubauer and Klebanoff. On the contrary, the mean transverse velocity was found to be zero within the measurement uncertainties in the experiment of Simpson, Chew and Shivaprasad. It is believed that the assumption $\left(\overline{w^{\prime 2}}=\overline{v^{\prime 2}}\right)$ does not greatly affect the results of the present work.

In order to establish the accuracy which should be expected from correlations established on the basis of the afore-mentioned data (Tab. I), a note on the uncertainties of measurement is appropriate, especially since data from different experimental setups and instrumentation are used. Simpson, Chew and Shivaprasad [4] estimated that using laser anemometry the values of $\overline{u^{\prime 2}}$ and $\overline{v^{\prime 2}}$ were measured to $\pm 4 \%$ of the maximum profile value. Considering the form of the $\overline{u^{\prime 2}}$ and $\overline{v^{\prime 2}}$ profiles this corresponds to an average $\pm 8 \%$ uncertainty. When using crosshot-wire anemometry [4] the values of $\overline{u^{\prime 2}}$ and $\overline{v^{\prime 2}}$ were measured with an estimated uncertainty of $\pm 10 \%$. This accuracy is about the best achieved in the experiments used in the present work (Tab. I). Furthermore when considering quantities involving sums of $\overline{u^{\prime 2}}$ and $\overline{v^{\prime 2}}$ (Eqs. (3) and (4)) a $\pm 20 \%$ uncertainty is to be expected if $\overline{u^{\prime 2}}$ and $\overline{v^{\prime 2}}$ are known individually to $\pm 10 \%$. Furthermore the assumption $\left.\overline{\left(w^{\prime 2}\right.}=\overline{v^{\prime 2}}\right)$ used in the present work introduces further uncertainties in the determination of quantities dependent on $\overline{w^{\prime 2}}$ (Eq. (4)).

Table I. - Summary of the experiments used in establishing the correlations

\begin{tabular}{|c|c|c|c|}
\hline Experiment & $M$ & $H_{12_{\mathrm{k}}}$ & Description \\
\hline Schubauer, Klebanoff [2] & $0.06-0.14$ & $1.30-2.80$ & $\begin{array}{l}\text { incompressible incipiently } \\
\text { separated (hot-wire) }\end{array}$ \\
\hline $\begin{array}{l}\text { Simpson, Chew } \\
\text { Shivaprasad [20] }\end{array}$ & $0.04-0.06$ & $1.32-9.45$ & $\begin{array}{l}\text { incompressible separated } \\
\text { (2-directional laser) }\end{array}$ \\
\hline Copy, Reisz [21] & $0.81-1.32$ & $1.30-2.65$ & $\begin{array}{l}M=1.30 \text { shock-wave/turbulent boundary-layer } \\
\text { interaction (2-directional laser) }\end{array}$ \\
\hline $\begin{array}{l}\text { Délery Copy } \\
\text { Reisz [22] }\end{array}$ & $0.80-1.36$ & $1.27-40.50$ & $\begin{array}{l}M=1.36 \text { shock-wave/turbulent boundary-layer } \\
\text { interaction (2-directional laser) }\end{array}$ \\
\hline $\begin{array}{l}\text { Kussoy, Horstman } \\
\text { Acharya }[23]\end{array}$ & $1.85-2.27$ & $1.33-1.57$ & $\begin{array}{l}\text { attached compressible } \\
\text { axisymmetric (hot-wire) }\end{array}$ \\
\hline
\end{tabular}

\section{Modeling approach.}

It is well established that the turbulent boundarylayer mean-velocity profile is adequately described by a 2-parameter family of profiles [26, 27]. From REVUE DE PHYSIQUE APPLIQUÉE. - T. 24, N`3, MARS 1989 this experimentally verified assumption span various integral methods for the computation of turbulent boundary-layer development. These methods were initially developed and applied to incompressible flows, but were successfully extended to compress- 
ible ones using a simple compressibility transformation for the mean-velocity profile. This transformation was introduced by van Driest [28] in order to account for mean density variations in the boundarylayer.

The application of correlations developed for incompressible flows to compressible ones is based on the hypothesis advanced by Morkovin [29] that turbulence structure is not affected by compressibility as long as the fluctuation Mach-number remains small with respect to unity, or equivalently the density fluctuations are negligible compared to the mean density. Experimental findings corroborate that this hypothesis is valid for boundary-layer flows up to external-flow Mach-numbers of 5 [29-31]. Then since in classical boundary-layer theory [14] the mean-velocity profile of an equilibrium boundary-layer depends only on shear-stress distribution and external-flow pressure-gradient, it is affected by compressibility only through mean-density variations. This leads to using correlations between kinematic integral quantities of the boundary-layer. For instance, instead of the displacement thickness $\left(\delta_{1}=\int_{0}^{\delta}\left(1-\bar{\rho} \bar{u} / \rho_{\mathrm{e}} u_{\mathrm{e}}\right) \mathrm{d} y\right)$ the kinematic displacement thickness $\left(\delta_{1_{\mathrm{k}}}=\int_{0}^{\delta}\left(1-\bar{u} / u_{\mathrm{e}}\right) \mathrm{d} y\right)$ is used. In the same way, it will be attempted to derive correlations for the kinematic normal fluctuation integrals,

$$
A_{\mathrm{k}}=\int_{0}^{\delta} \frac{\overline{u^{\prime 2}}-\overline{v^{\prime 2}}}{u_{\mathrm{e}}^{2}} \mathrm{~d} y
$$

and,

$$
B_{\mathrm{k}}=\int_{0}^{\delta} \frac{\bar{u}}{u_{\mathrm{e}}} \frac{3 \overline{u^{\prime 2}}-\overline{v^{\prime 2}}+\overline{w^{\prime 2}}}{u_{\mathrm{e}}^{2}} \mathrm{~d} y
$$

respectively. The boundary-layer shape-factor $H_{12_{k}}$ which characterizes the mean-velocity profile has a decisive influence upon turbulence stucture, and has been used in this respect by various authors [32, 33]. It will be one of the basic parameters in the present work. Instead of $H_{12_{\mathrm{k}}}$ the shape-parameter $J_{12_{\mathrm{k}}}$

$$
J_{12_{\mathrm{k}}}=1-\frac{1}{H_{12_{\mathrm{k}}}}
$$

will be used. This parameter is more convenient than $H_{12_{\mathrm{k}}}$ when flows with large separation, where $H_{12_{\mathrm{k}}}$ increases rapidly, are considered. The shapeparameter $J_{12_{\mathrm{k}}}$ increases with increasing $H_{12_{\mathrm{k}}}$ and tends to unity when $H_{12 \mathrm{k}}$ tends to infinity.

\section{Integrals correlations.}

In order to correlate the integrals $A_{\mathrm{k}}$ and $B_{\mathrm{k}}$ in a 2parametric fashion a second parameter besides $J_{12_{k}}$, such as a length-scale, is needed. The value of $A_{\mathrm{k}}$ scaled by $\delta_{1_{\mathrm{k}}}$ is plotted in figure 1 versus $J_{12_{\mathrm{k}}}$ for the incompressible flow data (Tab. I), establishing a plausible correlation. However, when considering the compressible flow data (Tab. I), this correlation is invalidated (Fig. 2). Although the attached compressible boundary-layer data of Kussoy agree with the incompressible correlation, the shock-wave/turbulent boundary-layer interaction data of Copy and Délery exhibit substantially higher values for the same shape-parameter.

This difference in behaviour is in accordance with other observations on shock-wave/turbulent boundary-layer interactions. Bradshaw [31] states that although Morkovin's hypothesis is independent of external-flow pressure-gradient one must always expect changes in turbulence structure if rates-of-

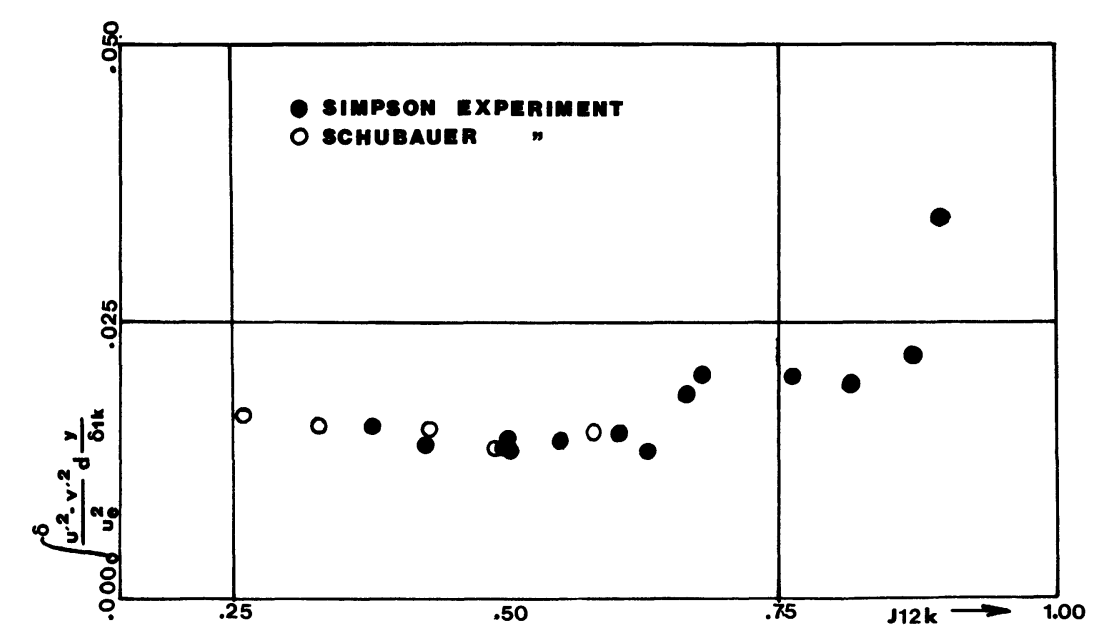

Fig. 1. - Correlation concerning the normal fluctuation terms in incompressible boundary-layers. The experiments from which the data are taken are described in table I. 


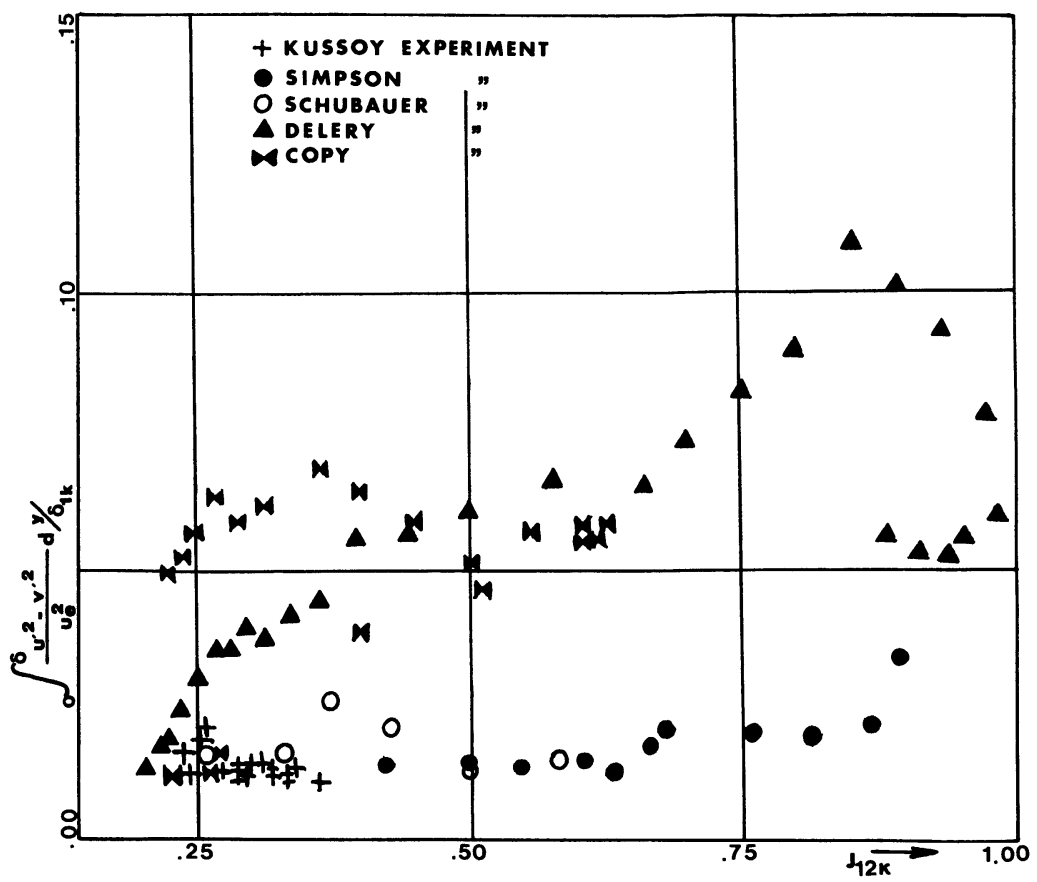

Fig. 2. - Normal fluctuation terms representation showing, compared with figure 1, that correlation schemes valid for incompressible flows are not necessarily valid for compressible flows as well. The experiments from which the data are taken are described in table $\mathrm{I}$.

strain other than the mean shear become appreciable, so that the hypothesis would fail in the presence of shock-waves and expansion-fans where the dilatation $\operatorname{div} \mathbf{V}$ is large. Délery [7] observes departure from equilibrium in shock-wave/turbulent boundary-layer interactions. In general the strong turbulence amplification in the longitudinal direction, associated with increased longitudinal mean rate-of-strain suggests strong history effects, both in incompressible [4, 11] and compressible [7] flow.
Examination of the experimental data suggested that the choice of $\delta_{1_{k}}$ as length-scale was not adequate. When using the boundary-layer thickness $\delta$ as length-scale, the data clearly form a hysteresis loop (Fig. 3). The lower part of this loop corresponds to $\left(\mathrm{d} J_{12_{k}}>0\right)$ flows and the upper part to $\left(\mathrm{d} J_{12_{k}}<0\right)$ flows, so that a boundary-layer undergoing separation and then reattachment would be displaced counter-clockwise along the loop. This hysteresial behaviour was also observed by Délery [7].

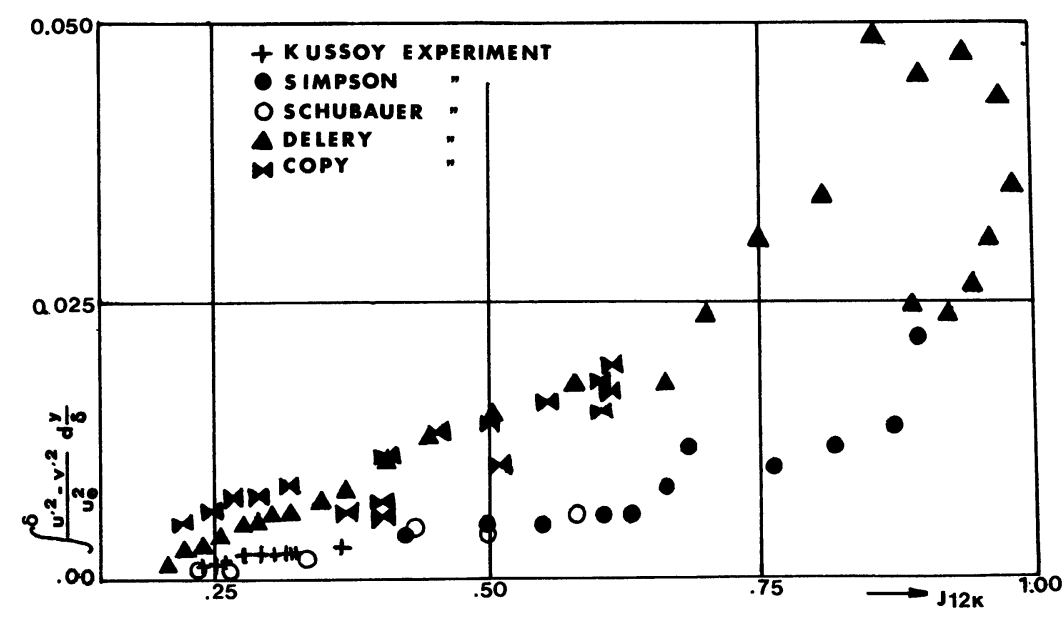

Fig. 3. - Representation of the normal fluctuation terms indicating a hysteresis behaviour. The experiments from which the data are taken are described in table $I$. 
The above observations suggested that a different length-scale should be associated with increasing and decreasing values of $J_{12_{k}}$, respectively. The following length-scale,

$$
\ell_{\mathrm{k}}=\left[\begin{array}{lll}
\delta & \text { if } & \mathrm{d} J_{12_{\mathrm{k}}}<0 \\
\delta-\delta_{1_{\mathrm{k}}} & \text { if } & \mathrm{d} J_{12_{\mathrm{k}}}>0
\end{array}\right.
$$

was found to describe rather well the hysteresis behaviour exhibited by the data. The $A_{\mathrm{k}}$-data are plotted in figure 4, using the length-scale $\ell_{\mathrm{k}} / \sqrt{\delta_{1_{\mathrm{k}}} / \delta}$. The use of the ratio $\delta_{1_{\mathrm{k}}} / \delta$ in the definition of the length-scale for $A_{\mathrm{k}}$ ameliorates the correlation of the data. The data of figure 4 indicate clearly a common behaviour which may be represented by a correlation of the form,

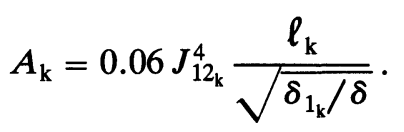

From the discussion on experimental data uncertainties it follows that, neglecting uncertainties concerning the mean-flow quantities, $A_{\mathrm{k}}$ (Eq. (5)) is known to $\pm 20 \%$. The correlation of equation (9) and the $\pm 20 \%$ envelope are plotted in figure 4 . There is, in general, fairly good agreement. However, it seems that the precision deteriorates for small values of $J_{12_{\mathrm{k}}}$. This discrepency may be attributed to further uncertainties associated with meanflow quantities and especially the boundary-layer thickness, which is used in defining the length-scale $\ell_{\mathrm{k}}$ (Eq. (8)). The effect of this uncertainty is expected to be more noticeable for small values of $A_{\mathrm{k}}$ and this might be responsible for the scatter observed in the data $\left(J_{12_{k}}<0.5\right)$.

In much the same way, a correlation was constructed for $\boldsymbol{B}_{\mathrm{k}}$. In this case, however, it was found that the energy thickness in the form of the shape- factor $H_{13_{\mathrm{k}}}$ had an appreciable influence, so that the length-scale $\ell_{\mathrm{k}} / H_{13_{\mathrm{k}}}$ was used. The data, plotted in figure 5, exhibit a consistent behaviour which may be represented by a correlation of the form,

$$
B_{\mathrm{k}}=\left(0.6 J_{12_{\mathrm{k}}}^{6}+0.05 J_{12_{\mathrm{k}}}\right) \frac{\ell_{\mathrm{k}}}{H_{13_{\mathrm{k}}}} .
$$

The uncertainty in evaluating the quantity $B_{\mathrm{k}}$ (Eq. (6)) is expected to be higher because of the use of the assumption $\left(\overline{w^{\prime 2}}=\overline{v^{\prime 2}}\right)$. Although this effect is not exactly quantifiable, it is believed that $B_{\mathrm{k}}$ was at best evaluated to $\pm 25 \%$. The proposed correlation (Eq. (10)) and the $\pm 25 \%$ envelope are plotted in figure 5. Most of the data fall within the $\pm 25 \%$ envelope and the uncertainty in determining $\delta$ could account for some of the scatter.

Examination of the correlations (Fig. (4) and (5)) suggests that the influence of the normal fluctuation terms on the mean momentum and mean kinetic energy balance becomes appreciable only for values of $H_{12_{k}}$ high enough for the boundary-layer to be near separation or separated. Their influence increases with increasing $H_{12_{\mathrm{k}}}$, that is increasing backflow. In attached turbulent boundary-layers $\left(J_{12_{\mathrm{k}}}<0.5, H_{12_{\mathrm{k}}}<2\right)$ the value of $A_{\mathrm{k}}$ is less than $4 \%$ of $\delta_{2_{\mathrm{k}}}$, as it may be readily seen from figure 1 . Consequently the influence of $A_{\mathrm{k}}$ on the integral mean-momentum equation (Eq. (1)) is negligible for attached turbulent boundary-layers $\left(H_{12_{k}}<2\right)$. This suggests that the scatter observed in the data for small values of $H_{12_{\mathrm{k}}}$ (Fig. 4), which was attributed to uncertainties in determining $\delta$, is of no practical significance. When the turbulent boundary-layer separates $A_{\mathrm{k}}$ increases rapidly. In the range $\left(J_{12_{\mathrm{k}}}>\right.$ $\left.0.75, H_{12_{\mathrm{k}}}>4\right)$ the magnitude of $A_{\mathrm{k}}$ is comparable to $\delta_{2_{\mathrm{k}}}$. For instance, at $\left(J_{12_{\mathrm{k}}}=0.9, H_{12_{\mathrm{k}}}=10\right)$ assuming

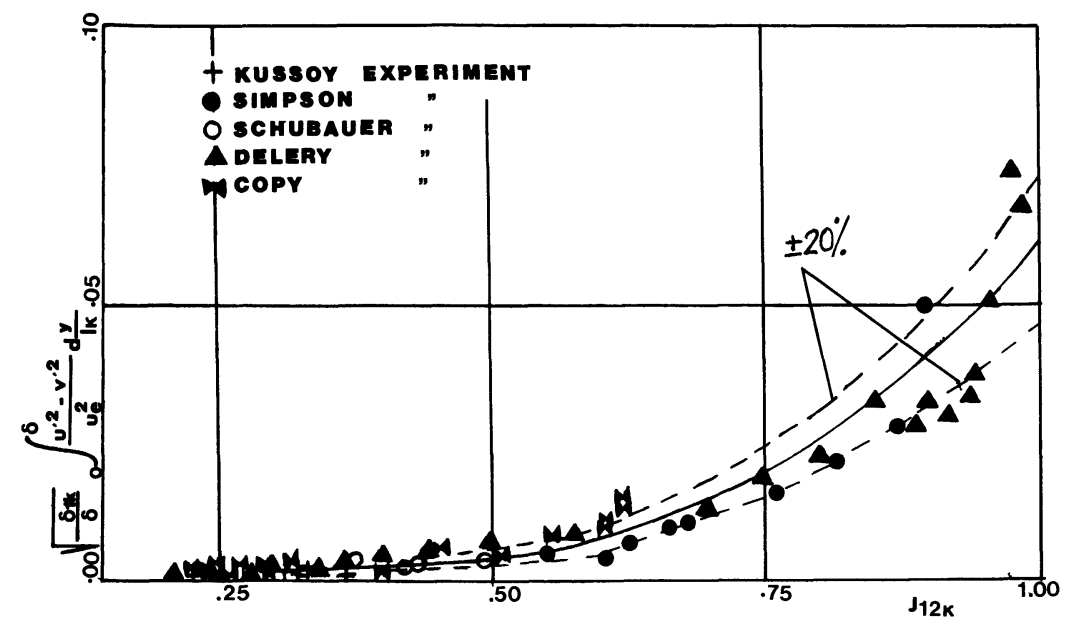

Fig. 4. - The final correlation for the quantity $A_{\mathrm{k}}$ appearing in the integral mean momentum equation. The experiments from which the data are taken are described in table I. 


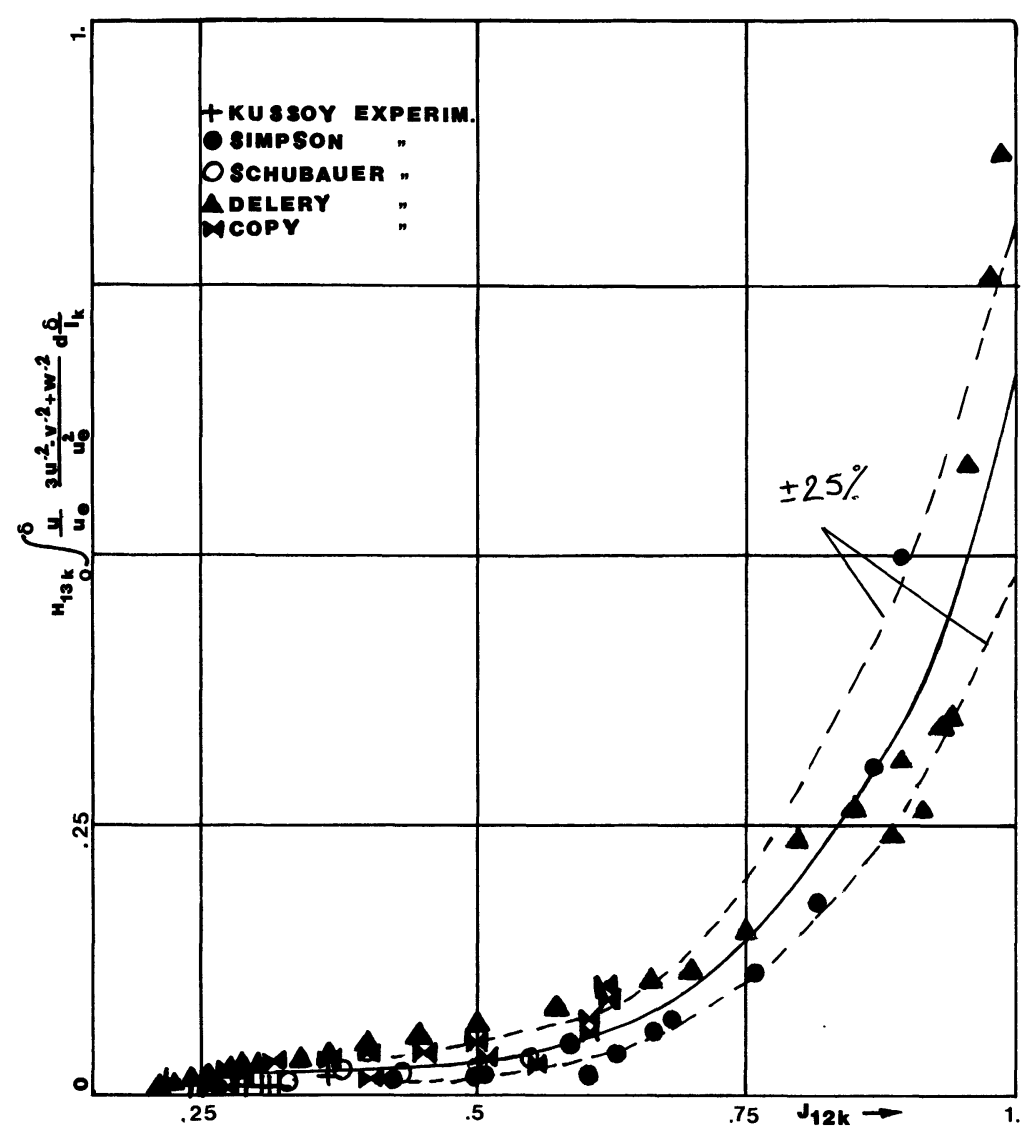

Fig. 5. - The final correlation for the quantity $B_{\mathrm{k}}$ appearing in the integral mean kinetic energy equation. The experiments from which the data are taken are described in table $\mathrm{I}$.

according to the experimental data that $\left(\delta \cong 2 \delta_{1_{\mathrm{k}}}\right.$, $H_{12_{\mathrm{k}}}=10$ ), the correlation of equation (9) estimates that $A_{\mathrm{k}}$ is about $50 \%$ of $\delta_{2_{\mathrm{k}}}$. Hence $A_{\mathrm{k}}$ may not be neglected in the integral mean-momentum equation for separated turbulent boundary-layers. Furthermore, it should be noted that the effect of the normal fluctuation terms upon the mean-momentum balance appears through the streamwise variation of $A_{\mathrm{k}}$ (Eq. (1)), so that $\pm 20 \%$ uncertainty in determining $A_{\mathrm{k}}$ seems acceptable for practical purposes. Similar remarks apply to the behaviour of $B_{\mathrm{k}}$ with respect to $\delta_{3_{k}}$. On the basis of the above discussion it may be concluded that the proposed correlations (Eqs. (9) and (10)) provide good engineering accuracy for the determination of the integrals of the normal fluctuation terms. Also, the established correlations corroborate the importance of these integrals in the separated-flow region.

The correlations for the terms $A_{\mathrm{k}}$ and $B_{\mathrm{k}}$ have been successfully used in an integral turbulent boundary-layer prediction method [34]. In order to use these correlations, some compressibility transformation must be used to obtain A and B which appear in the integral boundary-layer equations (Eqs. (1) and (2)) from $A_{\mathrm{k}}$ and $B_{\mathrm{k}}$ respectively.
Consideration of the data revealed that the ratios $A / A_{\mathrm{k}}$ and $B / B_{\mathrm{k}}$ are simple functions of the externalflow Mach number [34]. In order to substantiate the usefulness of the correlations, the computed [34] and measured displacement thickness and incompressible shape-factor evolution for the shock-wave/turbulent boundary-layer interaction flow of Copy and Reisz [21] (Tab. I) are compared in figure 6. The abscissa is the wall curvilinear coordinate scaled on the boundary-layer thickness at the beginning of the interaction. The agreement between computation and experiment is quite satisfactory. The boundarylayer thickenning at the shock-wave foot and the subsequent relaxation process are predicted correctly. Comparisons of turbulent boundary-layer predictions, using the correlations developed above, with experimental data for several shockwave/turbulent boundary-layer interaction flows may be found in reference [34].

\section{Turbulence Structure.}

The shape-parameter $J_{12_{k}}$ has been used with success in describing the behaviour of turbulence structure in equilibrium boundary-layers [32, 33]. East and 


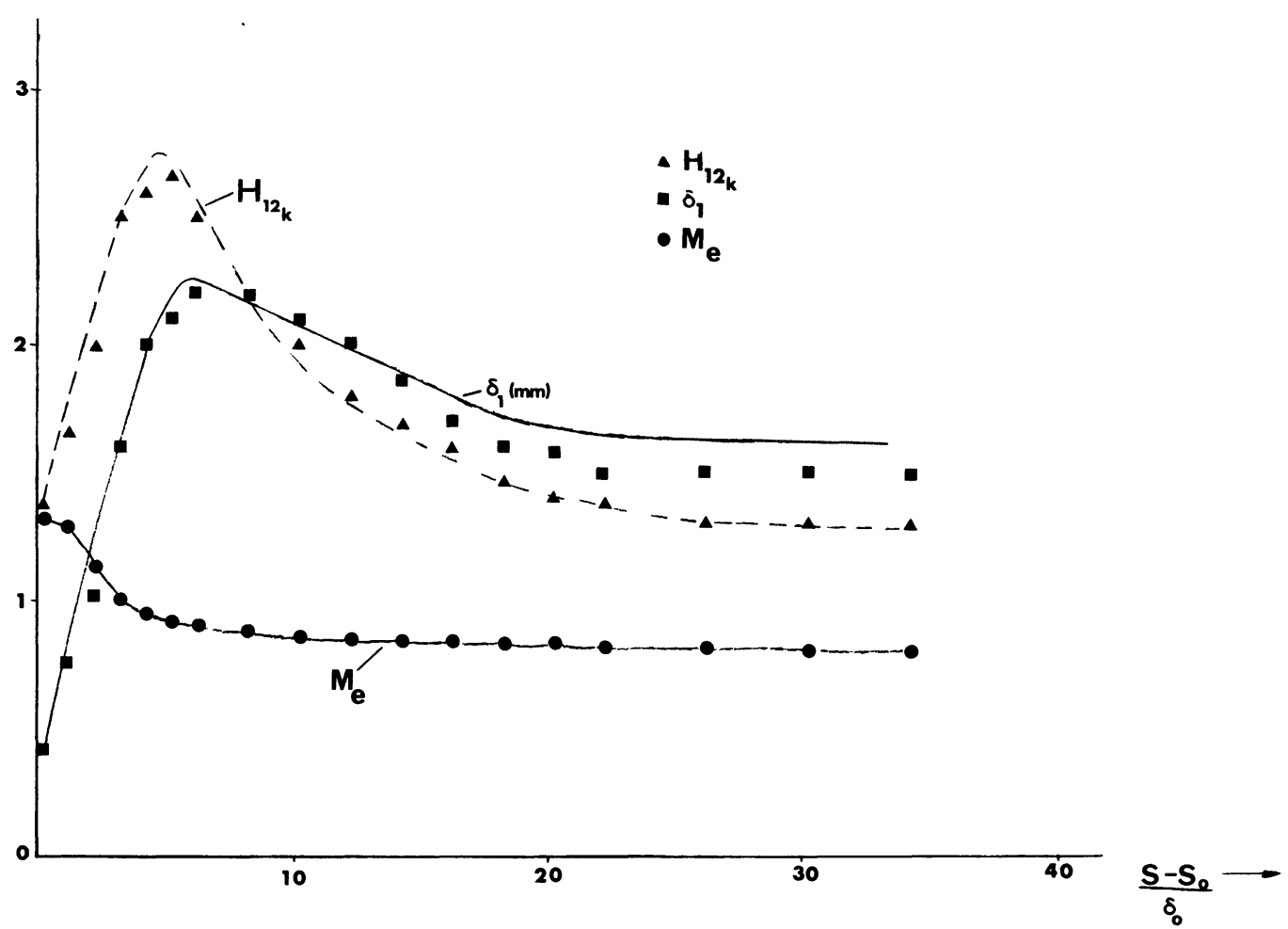

Fig. 6. - Comparison of predicted and measured boundary-layer parameters for the shock-wave/turbulent boundarylayer interaction flow of Copy and Reisz [21].

Sawyer [33] have established a linear functional relation between the maximum shear-stress coefficient $\sqrt{2 \tau_{\max } / \rho_{\mathrm{e}} u_{\mathrm{e}}^{2}}$ and the shape-parameter $J_{12 \mathrm{k}}$. Délery [7] found that this relation is not valid for shock-wave/turbulent boundary-layer interaction flows, including the experiments 3 and 4 (Tab. I). The data indicate a shear-stress lag in the interacting and separating boundary-layer $\left(\mathrm{d} J_{12_{\mathrm{k}}}>0\right)$ and a hysteresial shear-stress lead during the reattachment and the subsequent relaxation processes $\left(\mathrm{d} J_{12_{\mathrm{k}}}<0\right)$.

The correlations established in the first part of this work indicate that it is possible to use the shapeparameter $J_{12_{\mathrm{k}}}$ in describing the behaviour of turbulence in nonequilibrium boundary-layers that is boundary-layers where the equilibrium-parameter $[3,18,33]$

$$
\beta=\frac{\delta_{1_{\mathrm{k}}}}{\tau_{\mathrm{w}}} \frac{\mathrm{d} p}{\mathrm{~d} x}
$$

is not constant streamwise. This parameter which is a nondimensional streamwise pressure-gradient is essential in equilibrium turbulent boundary-layer theory $[32,33,35,36]$. In equilibrium turbulent boundary-layers the shape-parameter $J_{12_{\mathrm{k}}}$ is related to any other parameter of the mean-velocity profile through the equilibrium parameter $\beta$. In nonequilibrium turbulent boundary-layers however, the equilibrium relation is not valid and another parameter together with the shape-parameter $J_{12_{\mathrm{k}}}$ is necessary for describing the boundary-layer properties. These 2 parameters define using the equilibrium relation an equilibrium parameter which is inconsistent with the local external-flow pressure-gradient and the mean-velocity profile. This uncoupling of the meanvelocity profile and the external-flow pressure-gradient is an essential feature of integral turbulent boundary-layer computation methods, because it allows for history effects and departure from equilibrium $[18,35,37]$. The correlations established above (Eqs. (9) and (10)) corroborate that such a 2-parametric modeling is applicable to the boundary-layer turbulence properties. In view of this discussion the turbulence structure of Table I experiments is examined in the following. It was found that the behaviour of the maximum value of the $\overline{u^{\prime 2}}$ profile could be described by a correlation, presented in figure 7 , of the form

$$
\sqrt{\overline{u_{\max }^{\prime 2}}}=0.125 J_{12_{\mathrm{k}}}^{4} \frac{u_{\mathrm{e}}}{\left[\delta_{1_{\mathrm{k}}} / \delta\right]^{2}} .
$$

The proposed correlation and the $\pm 10 \%$ envelope are plotted in figure 7 . The representation of the data is quite satisfactory. Again, the uncertainty in determining $\delta$ may account for some of the scatter.

Attempts to model the behaviour of the maximum value of the $\overline{v^{\prime 2}}$-profile in a way similar to the one used for $\overline{u^{\prime 2}}$ failed. This indicates that the behaviour 


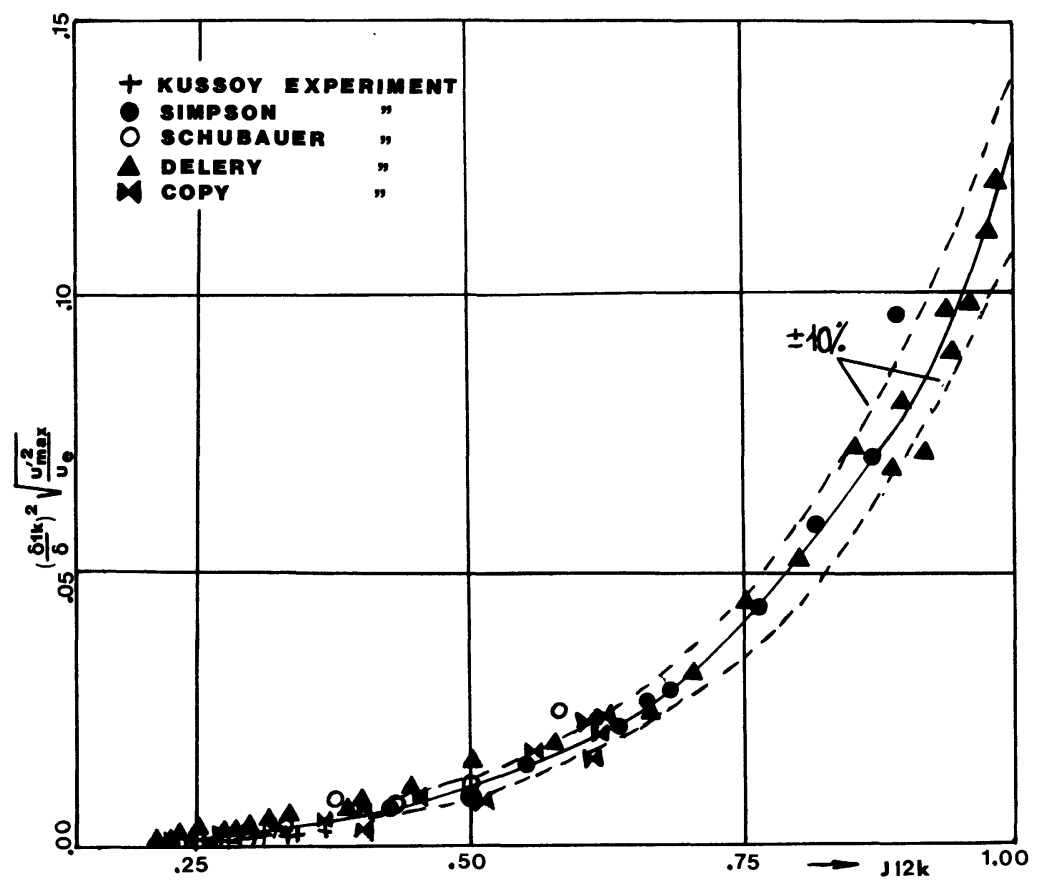

Fig. 7. - The final correlation concerning the maximum value of the $\overline{u^{\prime 2}}$-profile. The experiments from which the data are taken are described in table $\mathbf{I}$.

of the $\overline{v^{2}}$-component of the turbulence kinetic energy is fundamentally different from the behaviour of the $\overline{u^{\prime 2}}$-component, as may be seen for instance in figure 8. This is in accordance with observations made in shock-wave/turbulent boundary-layer interaction flows [7, 38, 39] which concluded that the turbulence kinetic energy is produced on the $\overline{u^{\prime 2}}$-component in the strong interaction region where the streamwise mean flow deceleration is very important. The turbulence kinetic energy is then redistributed between the $\overline{u^{\prime 2}}, \overline{v^{\prime 2}}$ and $\overline{w^{\prime 2}}$ components in a relaxation process which is mainly due to the pressure-strain correlations [39]. Similar observations were made for incompressible separated flows [4].

However, considering the quantity

$$
\alpha=\frac{\sqrt{\overline{u_{\max }^{\prime 2}}}-\sqrt{\overline{\overline{u_{\max }^{\prime 2}}}}}{u_{\mathrm{e}}}
$$

which is a measure of the anisotropy between the $\overline{u^{\prime 2}}$-component and the $\overline{v^{\prime 2}}$-component (Fig. 9), it

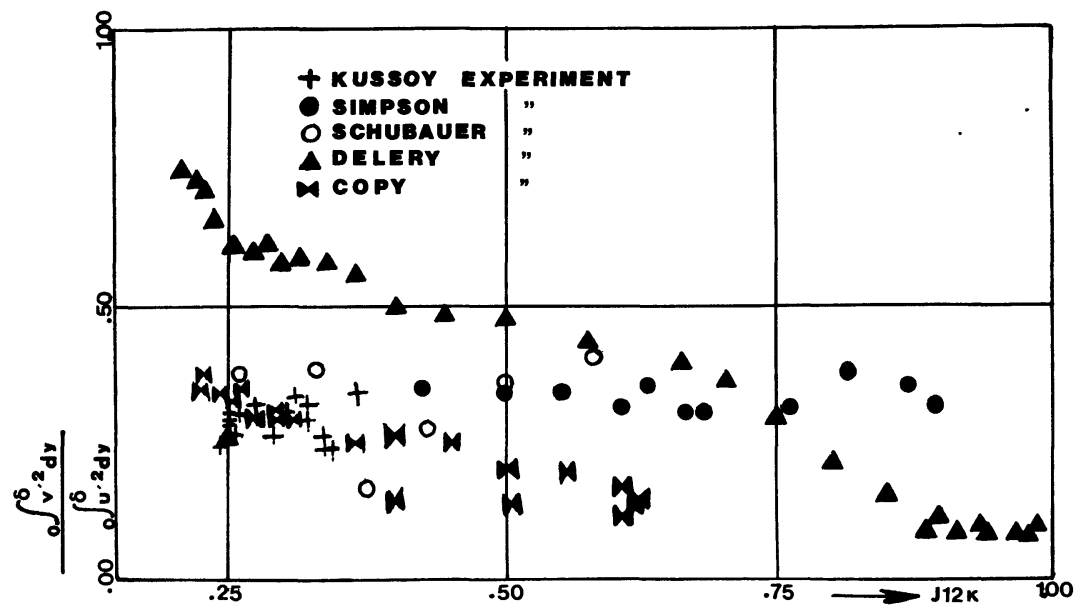

Fig. 8. - Representation of the ratio of the integrals of the normal fluctuation terms, indicating the difference in the behaviour of $\overline{u^{\prime 2}}$ and $\overline{v^{\prime 2}}$, especially in the case of shock-wave/turbulent boundary-layer interaction. The experiments from which the data are taken are described in table I. 


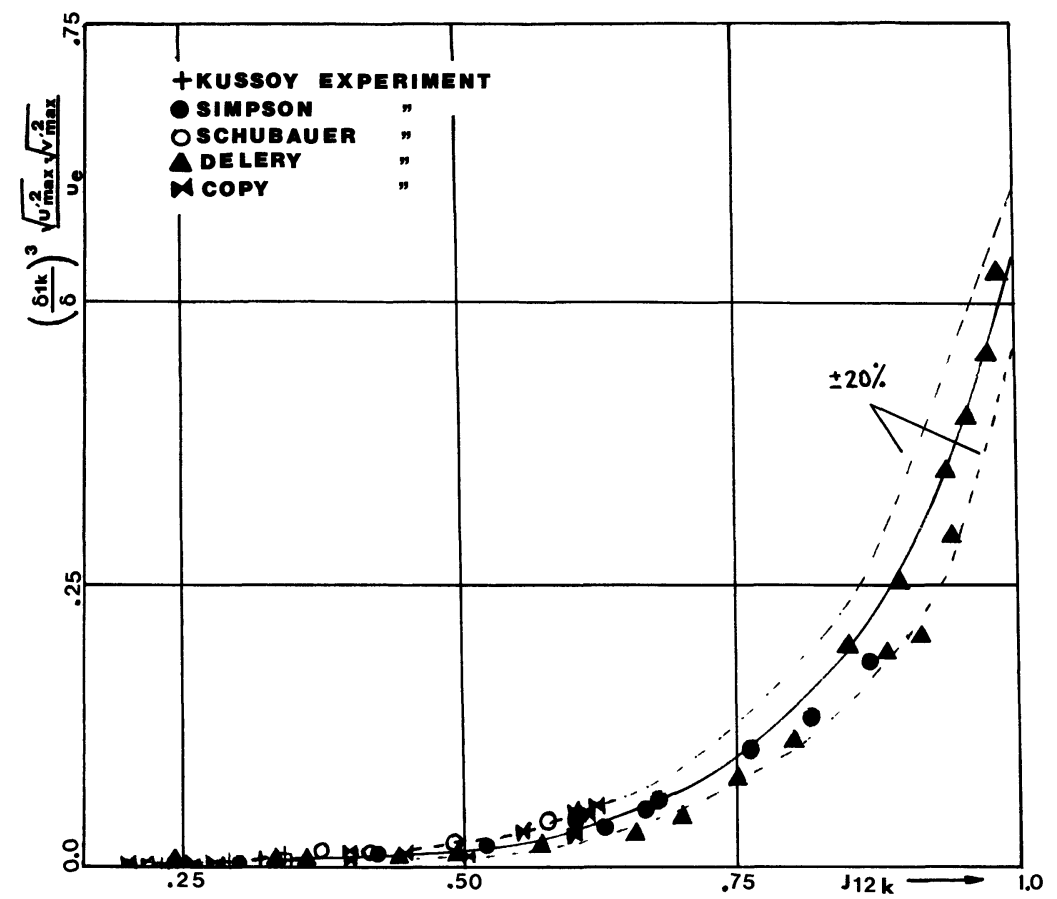

Fig. 9. - The final correlation for the quantity $\alpha$ (Eq. (13)). The experiments from which the data are taken are described in table I.

was possible to describe its behaviour by a relation of the form

$$
\alpha=0.53 J_{12_{\mathrm{k}}}^{6} \frac{1}{\left[\delta_{1_{\mathrm{k}}} / \delta\right]^{3}}
$$

The proposed correlation and the $\pm 20 \%$ envelop are plotted in figure 9 . Since it involves the difference between $\overline{u^{\prime 2}}$ and $\overline{v^{\prime 2}}$ a $\pm 20 \%$ uncertainty is expected. It is seen from figure 9 that the proposed correlation provides a fairly good description of the data to $\pm 20 \%$. Again, the uncertainties in determining $\delta$ may account for some of the scatter.

Examination of the correlations of figures 7 and 9 points out the previously discussed mechanism of turbulence production in the separated turbulent boundary-layer. The value of $\overline{u_{\max }^{\prime 2}}$ increases rapidly with increasing $J_{12_{\mathrm{k}}}$. On the contrary, $\overline{v_{\max }^{\prime 2}}$ does not follow the increase of $\overline{u_{\max }^{\prime 2}}$. Instead, the anisotropy between the 2 components increases with increasing $J_{12_{k}}$, as it may also be seen from figure 8 . In this respect the importance of the parameter $\delta_{1_{k}} / \delta$, associated with boundary-layer entrainment [40, 41], should be noted. This parameter is essential in the correlations of equations (12) and (14).

Délery [42] observed that in shock-wave/turbulent boundary-layer interactions resulting in flow separation, the separated flow region behaved similarly to 2 counter-flowing jets, one with the external-flow velocity and another with the maximum reverse-flow velocity. This similarity suggests the use $[14,42]$ of a nondimensional velocity

$$
\Phi=\frac{a-u_{\mathrm{N}}}{u_{\mathrm{e}}-u_{\mathrm{N}}}
$$

where $u_{\mathrm{N}}$ is the algebraic value of the maximum backflow velocity in the separated boundary-layer profile. Based on this nondimensional velocity the nondimensional length

$$
\xi=\frac{y-y_{\Phi=0.50}}{y_{\Phi=0.95}-y_{\Phi=0.50}}
$$

is defined. Plotting the values of $\sqrt{\overline{u^{\prime 2}} / \overline{u_{\max }^{\prime 2}}}$ versus $\xi$, for several of the separated boundary-layers of the experiments 2 and 4 (Tab. I) results in a fairly good correlation (Fig. 10). The data for the $\sqrt{\overline{v^{\prime 2}} / \overline{v_{\text {max }}^{\prime 2}}}$ profile exhibit an analogous behaviour (Fig. 11). Only several of the available data are plotted in figures 10 and 11 . Nevertheless, care was taken that the plotted data be representative of the existing scatter. It should be noted that the above modeling of the profiles of the normal fluctuation terms cannot be extended to attached flows by simply assuming $\left(u_{N}=0\right)$. Furthermore in the case of attached turbulent boundary-layers the $\overline{u^{\prime 2}}$-component profile differs from the $\overline{v^{\prime 2}}$-component profile, for instance in the location of their respective maxima [24].

It is felt that further work is needed in order to establish correlations for the profiles of $\sqrt{\overline{u^{\prime 2}} / \overline{u_{\max }^{\prime 2}}}$ 


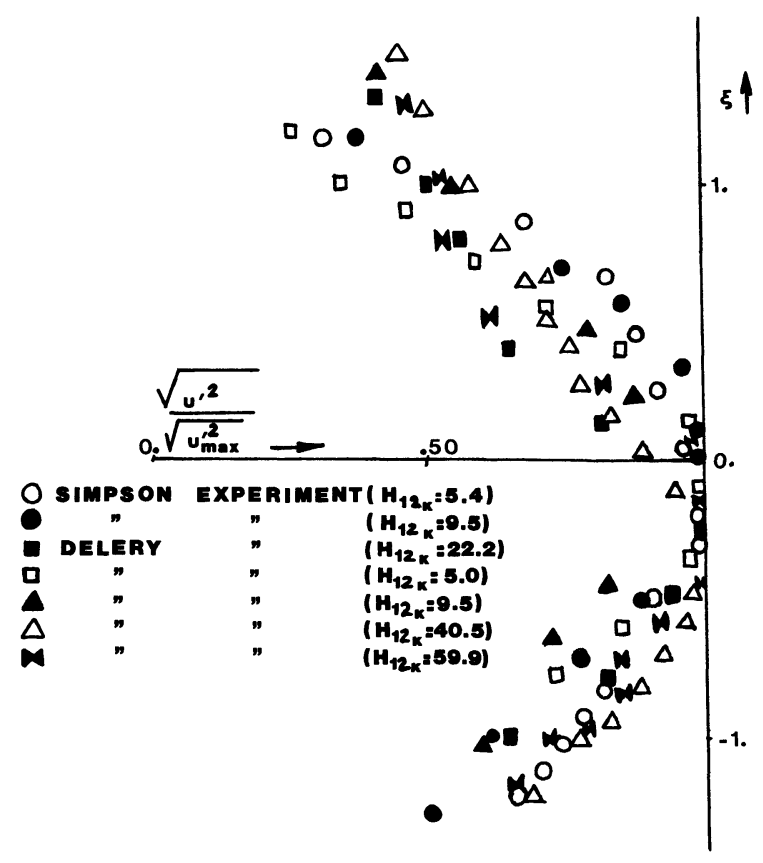

Fig. 10. - Representation of various $\sqrt{\overline{u^{\prime 2}}}$-profiles from detached turbulent boundary-layers. Several of the available profiles were plotted and chosen so as to be representative of the existing scatter. The experiments from which the data are taken are described in table $\mathrm{I}$.

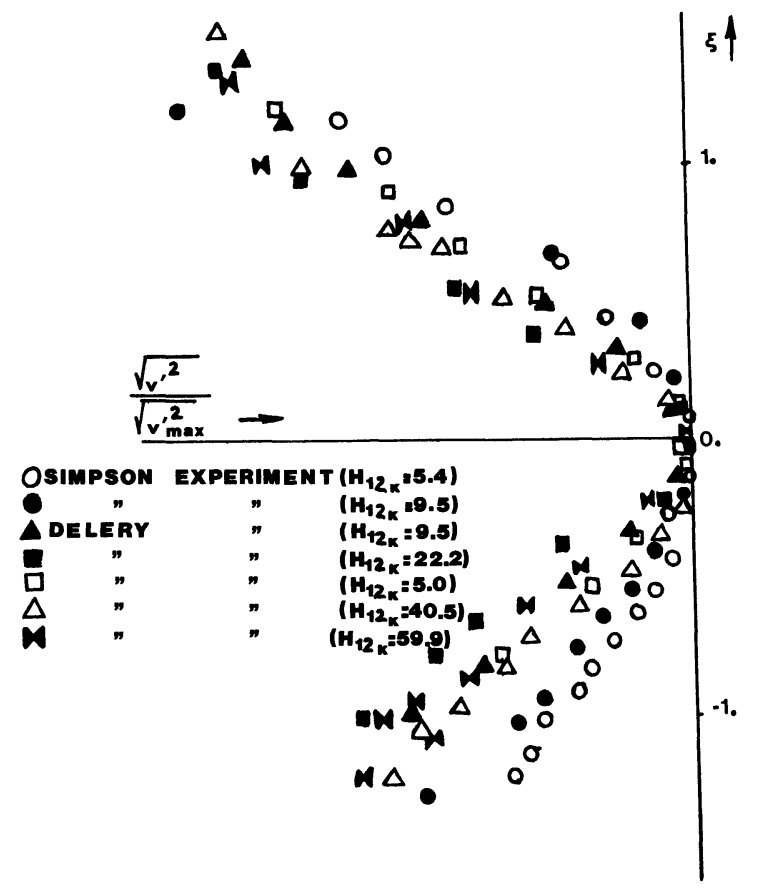

Fig. 11. - Representation of various $\sqrt{\overline{v^{\prime 2}}}$-profiles from detached turbulent boundary-layers. Several of the available profiles were plotted and chosen so as to be representative of the existing scatter. The experiments from which the data are taken are described in table I. and $\sqrt{\overline{v^{\prime 2}} / \overline{v_{\max }^{\prime 2}}}$. However, if such correlations are established, they may be used together with the correlations of figures 7 and 9 in determining the profiles of $\overline{u^{\prime 2}}$ and $\overline{v^{\prime 2}}$.

These results indicate that in largely separated turbulent boundary-layers the flow behaves mainly as a free shear-flow, the wall influence not reaching the maximum backflow region. On the contrary, in attached turbulent boundary-layers the influence of the wall is appreciable mainly through the effect of the mean rate-of-strain on the pressure-strain correlations [43, 44]. Rose [8] found that in a shockwave/turbulent boundary-layer interaction where the boundary-layer remained attached, the increase of the normal fluctuation terms was not substantial. It seems that the increase of turbulence kinetic energy is mainly connected to the boundary-layer mean-velocity profile development and the local streamwise rate-of-strain associated with the mechanism of separation and not to the externalflow pressure-gradient. This would explain the similar behaviour of turbulence structure in incompressible separated turbulent boundary-layers and shockwave/turbulent boundary-layer interaction separation (Figs. 7, 9, 10 and 11).

\section{Conclusions.}

Experimental data indicate that the normal fluctuation terms increase in separating and separated turbulent boundary-layers. Consequently their modeling is required for predicting such flows.

In this work, correlations have been developed for the integrals of the normal fluctuation terms which appear in integral turbulent boundary-layer computation methods. These correlations are valid both for attached and detached, incompressible and compressible turbulent boundary-layers. They are also valid in the case of shock-wave/turbulent boundarylayer interaction. Furthermore, correlations were developed for the maxima of the normal fluctuation terms. Finally, some properties of the turbulence structure in separated flows, both incompressible and resulting from shock-wave/turbulent boundarylayer interaction are discussed.

These correlations indicate that the turbulence structure in the boundary-layer depends rather on the global shape of the mean-velocity profile (through parameters such as $J_{12_{\mathrm{k}}}$ ) than on the local velocity gradient. They also corroborate that it is possible to use a 2-parametric representation for the separated boundary-layer turbulence structure, in much the same way as for the mean-velocity profile. Finally, the similarity in turbulence structure of an incompressible separated turbulent boundary-layer and one separated by a shock-wave should be noted.

Throughout this work the influence of some 
parameters affecting the boundary-layer turbulence structure, such as wall curvature, was omitted. Nevertheless, it is believed that this contribution will help to improve upon integral turbulent boundarylayer computation methods, by extending their validity in the separated-flow region.

\section{Acknowledgments.}

This work is a revised version of a paper, presented at the ASME 29th Gas Turbine Conference and Exhibit, held in June 1984, in Amsterdam, The Netherlands.

\section{References}

[1] Rubesin M. W. and Rose W. C., The Turbulent Mean-Flow, Reynolds-Stress, and Heat-Flux Equations in Mass-Averaged Dependent Variables, NASA TM X-62-248 (1973).

[2] Schubauer G. B. and Klebanoff P. S., Investigation of Separation of the Turbulent BoundaryLayer, NACA Report 1030 (1951).

[3] RotTA J., Turbulent Boundary-Layers in Incompressible Flow, Progress in Aeronautical Sciences, vol. 2 (1962) 1-219.

[4] Simpson R. L., Chew Y. T. and Shivaprasad B. G., The Structure of a Separating Turbulent Boundary-Layer, Part 1. Mean-Flow and Reynolds-Stresses, JFM, vol. 113 (1981) 23-51.

[5] Simpson R. L., Chew Y. T. and Shivaprasad B. G., The Structure of a Separating Turbulent Boundary-Layer, Part 2. Higher-Order Turbulence Results, JFM, vol. 113 (1981) 53-73.

[6] Shiloh K., Shivaprasad B. G. and Simpson R. L., The Structure of a Separating Turbulent Boundary-Layer, Part 3. Transverse Velocity Measurements, JFM, vol. 113 (1981) 75-90.

[7] DÉlERY J. M., Experimental Investigation of Turbulence Properties in Transonic ShockWave/Boundary-Layer Interactions, AIAA Journal, vol. 21 (Feb. 1983) 180-185.

[8] Rose W. C. and Johnson D. A., Turbulence in a Shock-Wave/Boundary-Layer Interaction, AIAA Journal, vol. 13 (Jul. 1975) 884-889.

[9] Hayakawa K., Smits A. J. and Bogdonoff S. M., Hot-Wire Investigation of an Unseparated Shock-Wave/Turbulent Boundary-Layer Interaction, AIAA Journal, vol. 22 (May 1984) 579585.

[10] Kuntz D. W., Amatucci V. A. and Addy A. L., Turbulent Boundary-Layer Properties Downstream of a Shock-Wave/Boundary-Layer Interaction, AIAA Journal, vol. 25 (May 1987) 668675.

[11] KIM J., KLINE S. J. and Johnston J. P., Investigation of a Reattaching Turbulent Shear-Layer : Flow over a Backward-Facing Step, ASME Journal of Fluids Engineering, vol. 102 (Sept. 1980) 302308.

[12] Chapman D. R., Computational Aerodynamics Development and Outlook, AIAA Journal, vol. 17 (Dec. 1979) 1293-1313.

[13] MCNally W. D. and Sockol P. M., Computational Methods for Internal Flows with Emphasis on Turbomachinery, NASA TM-82764 (1981).
[14] Schlichting H., Boundary-Layer Theory, Monograph, McGraw-Hill (1979).

[15] Ktenidis P., 3-D Axisymmetric Viscous Internal Flows on Rotating Surfaces in Turbomachines, $\mathrm{PhD}$ (1987) National Technical University, Athens, Greece.

[16] LeFoll J., A Theory of Representation of the Properties of Boundary-Layers on a Plane, presented at the VKI Seminar on Advanced Problems in Turbomachinery (1965) Brussels, Belgium.

[17] Papailiou K. D., Optimisation d'Aubages de Compresseur à Forte Charge sur la Base des Théories des Couches Limites, PhD (1969) Université de Liège, Liège, Belgium.

[18] Assassa G. M. and Papailiou K. D., An Integral Method for Calculating Turbulent BoundaryLayer with Separation, ASME Journal of Fluids Engineering, vol. 100, (March 1979) 110-116.

[19] Huo S., Blade Optimization Based on BoundaryLayer Concepts for Compressible Decelerating Flows, PhD (1973) VKI, Brussels, Belgium.

[20] Simpson R. L., Chew Y. T. and Shivaprasad B. G., Project SQUID Report SMU-4-PU (1980).

[21] CoPy C. and ReISZ J., Analyse Expérimentale d'une Interaction Choc-Couche Limite Turbulente à Mach 1.30 (Décollement Naissant), ONERA RT 42-7078 AY 014 (1980).

[22] Délery J., Copy C. and Reisz J., Analyse au Vélocimètre LASER 2-D d'une Interaction Choc-Couche Limite avec Décollement Etendu. ONERA RT 37-7078 AY 014 (1980).

[23] Fernholtz H. H. and Finley P. J., A Further Compilation of Compressible Boundary-Layer Data with a Survey of Turbulence Data, AGARD AG-263 (1981).

[24] KLEBANOFF P. S., Characteristics of Turbulence in a Boundary-Layer with a Zero Pressure-Gradient, NACA Report 1247 (1955).

[25] ACharya M., Effects of Compressibility on Boundary-Layer Turbulence, AIAA Journal, vol. 15 (March 1977) 303-304.

[26] Coles D. E., The Law of the Wake in the Turbulent Boundary-Layer, JFM, vol. 1 (1956) 191-226.

[27] KuHN G. D. and Nielsen J. N., Prediction of Turbulent Separated Boundary-Layers, AIAA Journal, vol. 12 (Jul. 1974) 881-882. 
[28] DRIEST E. R. van, Turbulent Boundary-Layers in Compressible Fluids, JAS, vol. 18 (1951) 145160.

[29] Morkovin M. V., Effects of Compressibility on Turbulent Flows, presented at the Colloquium on the Mechanics of Turbulence, Marseille, France (1964).

[30] LAufer J., Thoughts on Compressible Turbulent Boundary-Layers, NASA SP-216 (1969) 1-13.

[31] BRAdShaw P. and FerRIS D. H., Calculation of Boundary-Layer Development Using the Turbulent Energy Equation: Compressible Flow on Adiabatic Walls, JFM, vol. 46 (1971) 83-110.

[32] Bradshaw P., The Turbulence Structure of Equilibrium Boundary-Layers, NPL Aero Report 1184 (1966).

[33] EAST L. F. and SAwYER W. G., An Investigation of the Structure of Equilibrium Turbulent Boundary-Layers, AGARD CP-271, paper 6 (1979).

[34] Kallas J. and Papailiou K. D., A Method for the Calculation of the Interaction of a Turbulent Boundary-Layer and a Shock-wave, presented at the 8th ISABE (1987) Cincinnati, Ohio, U.S.A.

[35] Alber I. E. and CoAts D. E., Analytical Investigation of Equilibrium and Nonequilibrium Compressible Turbulent Boundary-Layers, AIAA Paper 69-689, 1969.

[36] Alber I. E., Similar Solutions for a Family of Separated Turbulent Boundary-Layers, AIAA Paper 71-203 (1971).
[37] LeEs L. and ReEves B., Supersonic Separated and Reattachment Laminar Flows : I. General Theory and Application to Adiabatic BoundaryLayer/Shock-Wave Interaction. AIAA Journal, vol. 2 (1964) 1907-1920.

[38] Ardonceau P. L., The Structure of Turbulence in a Supersonic Shock-Wave/Boundary-Layer Interaction, AIAA Journal, vol. 22 (Sept. 1984) 1254-1262.

[39] Ardonceau P. L., Lee D. H., Alziary Th. and GoETHALS R., Turbulence Behaviour in a Shock-Wave Boundary-Layer Interaction, AGARD CP-271 (1979).

[40] HEAD M. R., Entrainment in the Turbulent Boundary-Layers, ARC RM 3152 (1960).

[41] Kline S., Cantwell B. and Lilley G., Eds., Proceedings of the Conference on Complex Turbulent Flows, AFOSR-HTTM-STANFORD (1981).

[42] DÉlery J., Analyse du Décollement Résultant d'une Interaction Choc-Couche Limite Turbulente en Transsonique, La Recherche Aérospatiale (Nov. 1978) 305-320.

[43] RotTa J., Statistische Theorie nichthomogener Turbulenz. 1. Mitteilung, Z. Phys. 129 (1951) 547572.

[44] Launder B. E., Reece G. J. and Rodi W., Progress in the Development of a ReynoldsStress Turbulence Closure, JFM, 68 (1975) 537566. 